\title{
Comparison of Clinical Characteristics Between Patients With Different Causes of Vocal Cord Immobility
}

\author{
Min-Hyun Kim, $\mathrm{MD}^{1}$, Junsoo Noh, $\mathrm{MD}^{1}$, Sung-Bom Pyun, $\mathrm{MD}, \mathrm{PhD}^{1,2}$ \\ ${ }^{1}$ Department of Physical Medicine and Rehabilitation, Korea University College of Medicine, Seoul; \\ ${ }^{2}$ Brain Convergence Research Center, Korea University Anam Hospital, Seoul, Korea
}

\begin{abstract}
Objective To analyze the clinical characteristics between neurogenic and non-neurogenic cause of vocal cord immobility (VCI).

Methods The researchers retrospectively reviewed clinical data of patients who underwent laryngeal electromyography (LEMG). LEMG was performed in the bilateral cricothyroid and thyroarytenoid muscles. A total of 137 patients were enrolled from 2011 to 2016, and they were assigned to either the neurogenic or nonneurogenic VCI group, according to the LEMG results. The clinical characteristics were compared between the two groups and a subgroup analysis was done in the neurogenic group.

Results Among the 137 subjects, 94 patients had nerve injury. There were no differences between the neurogenic and non-neurogenic group in terms of demographic data, underlying disease except cancer, and premorbid events. In general characteristics, cancer was significantly higher in the neurogenic group than non-neurogenic group ( $\mathrm{p}=0.001$ ). In the clinical findings, the impaired high pitched ' $\mathrm{e}$ ' sound and aspiration symptoms were significantly higher in neurogenic group ( $\mathrm{p}=0.039$ for impaired high pitched ' $e$ ' sound; $\mathrm{p}=0.021$ for aspiration symptoms), and sore throat was more common in the non-neurogenic group ( $\mathrm{p}=0.014)$. In the subgroup analysis of neurogenic group, hoarseness was more common in recurrent laryngeal neuropathy group than superior laryngeal neuropathy group $(\mathrm{p}=0.018)$.

Conclusion In patients with suspected vocal cord palsy, impaired high pitched 'e' sound and aspiration symptoms were more common in group with neurogenic cause of VCI. Hoarseness was more frequent in subjects with recurrent laryngeal neuropathy. Thorough clinical evaluation and LEMG are important to differentiate underlying cause of VCI.
\end{abstract}

Keywords Vocal cord paralysis, Electromyography, Laryngeal nerves, Recurrent laryngeal nerve

Received March 15, 2017; Accepted April 27, 2017

Corresponding author: Sung-Bom Pyun

Department of Physical Medicine and Rehabilitation, Korea University Anam Hospital, 73, Inchon-ro, Seongbuk-gu, Seoul 02841, Korea. Tel: +82-2920-6471, Fax: +82-2-929-9951, E-mail: rmpyun@korea.ac.kr

ORCID: Min-Hyun Kim (http://orcid.org/0000-0001-8058-084X); Junsoo Noh (http://orcid.org/0000-0002-4100-9154); Sung-Bom Pyun (http://orcid. org/0000-0002-3471-9692).

@ This is an open-access article distributed under the terms of the Creative Commons Attribution Non-Commercial License (http://creativecommons.org/ licenses/by-nc/4.0) which permits unrestricted noncommercial use, distribution, and reproduction in any medium, provided the original work is properly cited. Copyright $\odot 2017$ by Korean Academy of Rehabilitation Medicine 


\section{INTRODUCTION}

Vocal cord immobility (VCI) is defined as various spectrum of motion impairment in the vocal cord. Although hoarseness is the main symptom in VCI, dysphonia, odynophonia, dysphagia, chronic cough, and laryngospasm can also occur [1,2]. Visual inspection by a laryngoscopy and electrophysiologic study, such as laryngeal electromyography (LEMG) can help to differentiate the neurogenic and non-neurogenic causes of VCI $[3,4]$.

The LEMG technique was first introduced by Weddel et al. [5], and needle electrode insertion in small muscles of larynx with assistance of laryngoscopy or in-surgery was first reported in 1950s [6-8], followed by the standardized percutaneous electrode insertion technique [9]. LEMG is not only helpful in diagnosing neuromuscular disorder in the larynx [10-12], but it can also be used in botulinum toxin or hyaluronic acid injection in vocal cord $[13,14]$.

In the process of first diagnosing VCI, various systemic diseases can be suspected from the symptoms. Viral or bacterial infections can attribute to post-infectious neuropathies $[15,16]$ and a wide spectrum of malignancies or tumors present as a paralysis. Also, VCI can be seen in systematic neurologic diseases such as myasthenia gravis, Charcot-Marie-Tooth disease, and multiple sclerosis [2]. With LEMG results, it aids to select other diagnostic tests and determine timing and type of treatments. Furthermore, LEMG results are useful in predicting negative outcomes and their findings can alter definitive treatments [17]. It is important to diagnose VCI of neurogenic causes and to affect treatment and prognosis. However, there are few research studies regarding the association between the clinical characteristics in VCI and LEMG results.

The aim of this study was to analyze the clinical characteristics between neurogenic and non-neurogenic cause of VCI patients. Furthermore, the researchers tried to compare the clinical characteristics between neurogenic and non-neurogenic VCI patients by the difference of the LEMG findings.

\section{MATERIALS AND METHODS}

\section{Subjects}

The researchers retrospectively reviewed clinical data of patients who underwent LEMG from the Department of Physical Medicine and Rehabilitation in Korea University Anam Hospital. A total of 137 patients, who underwent LEMG due to clinical symptoms of VCI or abnormal findings in laryngoscopy, were enrolled from January 2011 to December 2016. Motion abnormalities including vocal cord hypomobility or glottic insufficiency were considered as abnormal findings in the laryngoscopy [2] . All the patients who complained symptoms of dysphagia or were suspected to be at risk of aspiration carried out a videofluoroscopic swallowing study (VFSS). Penetration or aspiration was concluded by VFSS findings and the researchers used an 8-point penetration-aspiration scale (PAS) [18]. All subjects were assigned to either the neurogenic or non-neurogenic group, according to the LEMG results. The clinical characteristics were compared between the two groups and a subgroup analysis was done in neurogenic group.

\section{Laryngeal electromyography}

Before LEMG, all subjects filled out a questionnaire about their status of suspected vocal cord palsy. Along with questionnaire, general characteristics, clinical symptoms of subjects were collected. Physical examinations including tongue deviation, palpable neck mass, laryngeal elevation, gag reflex was also performed. During the LEMG, a pillow was placed behind the subjects' neck in supine position and the neck was extended. In this position, the researchers indicated thyroid cartilage and cricoid cartilage as surface landmarks of the larynx (Fig. 1).

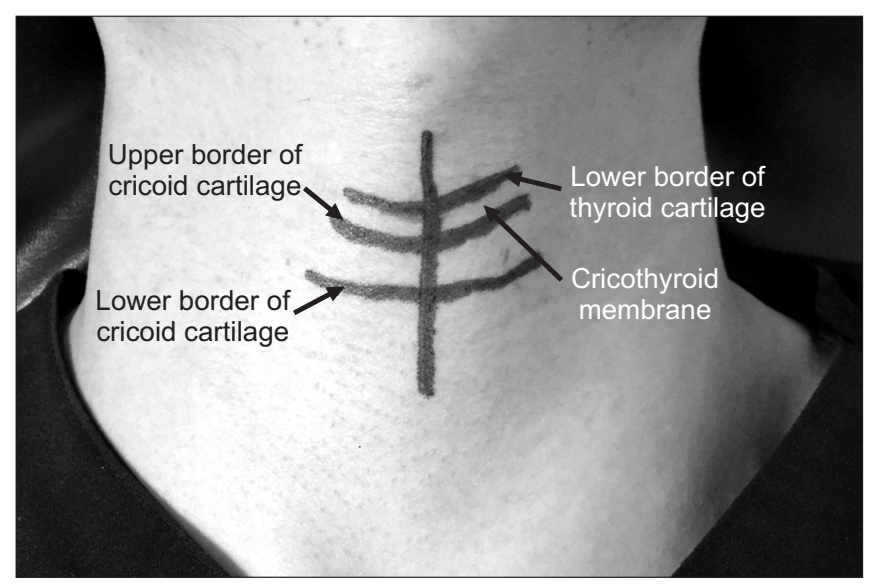

Fig. 1. Surface landmark of larynx is illustrated. We drew line to indicate lower border of thyroid cartilage, upper and lower borders of cricoid cartilage, midline of cricothyroid membrane. 
LEMG was performed by a single electromyographer (S. Pyun) using a Sierra Wave instrument (Cadwell Industries, Kennewick, WA, USA) and needle EMG was done with a 26-gauge $(0.46-\mathrm{mm}$ diameter), 5 - $\mathrm{cm}$ long monopolar needle electrode. Sweep speed was $10 \mathrm{~ms} / \mathrm{div}$ and sensitivity was $200 \mu \mathrm{V} / \mathrm{div}$. Needle EMG was performed in bilateral two small intrinsic muscles of the larynx: the cricothyroid and thyroarytenoid muscles. The cricothyroid is innervated by the superior laryngeal nerve (SLN) and produces tension and elongation of the vocal cord. The needle electrode was inserted into the skin tangentially to the upper border of the cricoid cartilage, superiorly, and laterally [19]. In order to activate the cricothyroid muscle, the subjects were asked to make ' $\mathrm{e}$ ' sound and to produce a high pitch as much as possible [20]. The thyroarytenoid is innervated by recurrent laryngeal nerve (RLN) and helps to reduce tension of the vocal cords during speech to decrease pitch. The needle electrode was inserted into the skin and the cricothyroid membrane. As the electrode passed the membrane, its direction was changed to $20^{\circ}$ laterally and $45^{\circ}$ superiorly or proximally [19]. In order to activate the thyroarytenoid muscle, subjects were asked to hold their breath after deep inspiration [20]. The researchers considered neurogenic VCI to be present with findings that abnormal spontaneous activities in the muscle at rest, polyphasic motor unit potentials, decreased, or reduced recruitment patterns $[3,21,22]$.

\section{Statistical analysis}

Statistical analysis was performed using SPSS Statistics

Table 1. Comparison of general characteristics between neurogenic and non-neurogenic group $(\mathrm{n}=137)$

\begin{tabular}{|c|c|c|c|}
\hline & Neurogenic $(n=94)$ & Non-neurogenic $(n=43)$ & p-value ${ }^{a, b)}$ \\
\hline Age (yr) & $56.56 \pm 17.34$ & $53.02 \pm 16.23$ & 0.660 \\
\hline Sex, male & $49(52.1)$ & $25(58.1)$ & 0.512 \\
\hline Duration of symptoms (day) & $41.24 \pm 36.60$ & $43.32 \pm 56.50$ & 0.818 \\
\hline \multicolumn{4}{|l|}{ Past history } \\
\hline Diabetes mellitus & $12(12.8)$ & $7(16.3)$ & 0.581 \\
\hline Hypertension & $24(25.5)$ & $10(23.3)$ & 0.775 \\
\hline Heart disease & $5(5.3)$ & $1(2.3)$ & 0.427 \\
\hline Stroke & $6(6.4)$ & $3(7.0)$ & 0.896 \\
\hline Cancer & $32(34.0)$ & $3(7.0)$ & $0.001^{*}$ \\
\hline Thyroid disease & $14(14.9)$ & $2(4.7)$ & 0.083 \\
\hline Thyroid operation & $9(9.6)$ & $1(2.3)$ & 0.130 \\
\hline \multicolumn{4}{|l|}{ Direct cause } \\
\hline Idiopathic & $28(33.3)$ & & \\
\hline Trauma & $8(8.5)$ & & \\
\hline Intubation & $25(26.6)$ & & \\
\hline Thyroid cancer & $12(12.8)$ & & \\
\hline Other malignancies & $11(11.7)$ & & \\
\hline Viral infection & $3(3.2)$ & & \\
\hline Brain tumor & $3(3.2)$ & & \\
\hline Stroke in medulla & $3(3.2)$ & & \\
\hline Laryngitis & $1(1.1)$ & & \\
\hline Trauma & $11(11.7)$ & $7(16.3)$ & $\mathrm{p}=0.462$ \\
\hline Intubation & $40(42.6)$ & $11(25.6)$ & $\mathrm{p}=0.057$ \\
\hline Infection & $22(23.4)$ & $10(23.3)$ & $\mathrm{p}=0.985$ \\
\hline
\end{tabular}

Values are presented as mean \pm standard deviation or number (\%).

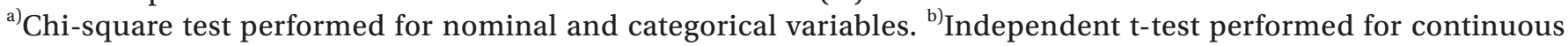
variables.

${ }^{*} \mathrm{p}<0.05$, significant difference between two groups. 
ver. 20 software (IBM, Armonk, NY, USA). Significance was determined when the p-value was less than 0.05 . Nominal and categorical variables were expressed with absolute number and relative frequencies. Chi-square test and multinomial logistic regression analysis were used to investigate the association between nominal and categorical variables. Continuous variables were analyzed by an independent t-test comparing the laryngeal neuropathy and normal groups. In the sub-group analysis, continuous variables were analyzed by analysis of variance (ANOVA).

\section{RESULTS}

Among the 137 subjects, 94 patients had nerve injury in RLN, SLN or both nerves, and other 43 patients had normal findings in LEMG. About one-fourth of the neurogenic VCI was idiopathic. When excluding idiopathic origin, $50 \%$ of the other patients had trauma or intubation history. Neurogenic VCI occurred commonly after treatment of malignancy including thyroid, parathyroid, lung, pancreas, and esophagus. Most malignancies are associated with lymph node metastasis or an invasion near the neck. Viral infection such as herpes zoster, Epstein-Barr virus, cerebellopontine angle mass, and stroke in the medulla also generated neurogenic VCI in some patients (Table 1). Most of the neurogenic VCI patients were treated with conservative therapies such as humidification, mucolytics, voice rest, and positional training initially. After conservative management, 34 patients received injection laryngoplasty, and 16 patients showed improvement of subjective symptoms. Steroid pulse therapy and voice therapy were considered as additional treatment options.

\section{Comparison between neurogenic and non-neurogenic group}

There were no significant differences between the neurogenic and non-neurogenic group in terms of demographic data and premorbid events. However, there was significantly higher tendency associated with cancer history in the neurogenic group than non-neurogenic group $(\mathrm{p}=0.001)$ (Table 1). In clinical findings, impaired high pitch 'e' sound and aspiration symptoms were more frequent in the neurogenic group and sore throat was more common in the non-neurogenic group $(\mathrm{p}<0.05)$ (Table 2$)$.

\section{Subgroup analysis in neurogenic group}

Results of subgroup analysis in neurogenic cause of VCI are presented in Table 3. Thyroid operation and infection history showed a correlation between three groups $(\mathrm{p}<0.05)$, however there were no significant differences between the RLN and SLN groups. Demographic data, underlying disease, and premorbid events except thy-

Table 2. Comparison of clinical characteristics between neurogenic and non-neurogenic group (n=137)

\begin{tabular}{|c|c|c|c|}
\hline & Neurogenic (n=94) & Non-neurogenic $(n=43)$ & p-value ${ }^{\text {a) }}$ \\
\hline \multicolumn{4}{|l|}{ Symptoms/signs } \\
\hline Voice change & $63(67.0)$ & $29(67.4)$ & 0.961 \\
\hline Hoarseness & $62(66.0)$ & $26(60.5)$ & 0.534 \\
\hline Aphonia & $3(3.2)$ & $0(0.0)$ & 0.236 \\
\hline Impaired high pitch & $55(58.5)$ & $17(39.5)$ & $0.039^{*}$ \\
\hline Breathing difficulty & $8(8.5)$ & $5(11.6)$ & 0.563 \\
\hline Sore throat & $5(5.3)$ & $8(18.6)$ & $0.014^{*}$ \\
\hline Aspiration during meal & $46(48.9)$ & $12(27.9)$ & $0.021^{*}$ \\
\hline \multicolumn{4}{|l|}{ Physical examination } \\
\hline Tongue deviation & $3(3.2)$ & $1(2.3)$ & 0.780 \\
\hline Palpable neck mass & $4(4.3)$ & $1(2.3)$ & 0.576 \\
\hline Impaired laryngeal elevation & $23(24.5)$ & $7(16.3)$ & 0.282 \\
\hline Decreased gag reflex & $13(13.8)$ & $4(9.3)$ & 0.456 \\
\hline
\end{tabular}

Values are presented as number (\%).

${ }^{a)} \mathrm{Chi}$-square test performed for nominal and categorical variables.

${ }^{*} \mathrm{p}<0.05$, significant difference between two groups. 
Table 3. Comparison between RLN and SLN groups ( $\mathrm{n}=94)$

\begin{tabular}{|c|c|c|c|c|c|}
\hline & RLN (n=57) & SLN (n=9) & Both $(n=28)$ & p-value ${ }^{a, b)}$ & p-value ${ }^{c)}$ \\
\hline Age (yr) & $57.84 \pm 16.60$ & $45.56 \pm 17.80$ & $57.50 \pm 18.04$ & 0.134 & \\
\hline Sex, male & $31(54.4)$ & $5(55.6)$ & $13(46.4)$ & 0.902 & 0.985 \\
\hline \multicolumn{6}{|l|}{ Past history } \\
\hline Diabetes mellitus & $7(12.3)$ & $0(0.0)$ & $5(17.9)$ & 0.098 & 0.993 \\
\hline Hypertension & $15(26.3)$ & $1(11.1)$ & $8(28.6)$ & 0.644 & 0.678 \\
\hline Heart disease & $5(8.8)$ & $0(0.0)$ & $0(0.0)$ & 0.081 & 0.997 \\
\hline Stroke & $2(3.5)$ & $1(11.1)$ & $3(10.7)$ & 0.187 & 0.121 \\
\hline Cancer & $20(35.1)$ & $3(33.3)$ & $9(32.1)$ & 0.279 & 0.993 \\
\hline Thyroid disease & $9(15.8)$ & $3(33.3)$ & $7(25.0)$ & 0.875 & 0.996 \\
\hline Thyroid operation & $2(3.5)$ & $3(33.3)$ & $4(14.3)$ & $0.020^{*}$ & 0.992 \\
\hline Trauma & $6(10.5)$ & $3(33.3)$ & $2(7.1)$ & 0.087 & 0.065 \\
\hline Intubation & $24(42.1)$ & $4(44.4)$ & $12(42.9)$ & 0.917 & 0.786 \\
\hline Infection & $12(21.1)$ & $0(0.0)$ & $10(35.7)$ & $0.012^{*}$ & 0.993 \\
\hline \multicolumn{6}{|l|}{ Subjective symptoms } \\
\hline Voice change & $35(61.4)$ & $6(66.7)$ & $22(78.6)$ & 0.264 & 0.663 \\
\hline Hoarseness & $42(73.7)$ & $3(33.3)$ & $17(60.7)$ & $0.034^{*}$ & $0.018^{*}$ \\
\hline Aphonia & $1(1.8)$ & $0(0.0)$ & $2(7.1)$ & 0.145 & 0.991 \\
\hline Impaired high pitch & $30(52.6)$ & $6(66.7)$ & $19(67.9)$ & 0.135 & 0.413 \\
\hline Breathing difficulty & $4(7.0)$ & $0(0.0)$ & $4(14.3)$ & 0.612 & 0.986 \\
\hline Sore throat & $2(3.5)$ & $0(0.0)$ & $3(10.7)$ & 0.166 & 0.991 \\
\hline Aspiration during meal & $30(52.6)$ & $3(33.3)$ & $15(46.4)$ & 0.613 & 0.353 \\
\hline \multicolumn{6}{|l|}{ Physical examination } \\
\hline Palpable neck mass & $4(7.0)$ & $0(0.0)$ & $0(0.0)$ & 0.176 & 0.996 \\
\hline Impaired laryngeal elevation & $12(21.1)$ & $2(22.2)$ & $9(32.1)$ & 0.790 & 0.489 \\
\hline Decreased gag reflex & $6(10.5)$ & $0(0.0)$ & $7(25.0)$ & 0.314 & 0.993 \\
\hline Abnormal findings in VFSS & $12(21.1)$ & $0(0.0)$ & $12(42.9)$ & 0.062 & 0.990 \\
\hline
\end{tabular}

Values are presented as mean \pm standard deviation or number (\%).

RLN, recurrent laryngeal neuropathy; SLN, superior laryngeal neuropathy; VFSS, videofluoroscopic swallowing study. ${ }^{a)}$ Multinomial logistic regression analysis performed for nominal and categorical variables. ${ }^{\text {b) }}$ ANOVA performed for continuous variables. ${ }^{c)}$ p-value between RLN and SLN groups by multinomial logistic regression analysis.

${ }^{*} \mathrm{p}<0.05$, significant difference.

roid operation and infection history were also not different between recurrent laryngeal and superior laryngeal groups (Table 3). Hoarseness had significant correlation between the three groups ( $\mathrm{p}=0.034$ ) and was significantly higher in patients with recurrent laryngeal neuropathy than superior laryngeal neuropathy $(\mathrm{p}=0.018)$.

\section{Subgroup analysis according to lesion location} confirmed by LEMG

A total 91 patients completed a laryngoscopy, of which 88 patients showed abnormal findings in the laryngoscopy. Among the 88 patients, 31 patients showed no ab- normal findings in LEMG, 3 patients showed no correlation between laryngoscopy and LEMG findings in terms of lesion location. Therefore, 54 patients (61.4\%) showed a correlation in site of lesion between the two examinations.

Because the whole neurogenic VCI patients did not complete laryngoscopy, the researchers divided three groups according to lesion location through LEMG findings. There was significant correlation between the three groups about intubation history and aphonia $(\mathrm{p}<0.05)$. However, no significant differences were detected when the researchers compared the right and left VCI groups. 
Table 4. Comparison according to lesion location confirmed by laryngeal electromyography $(\mathrm{n}=94)$

\begin{tabular}{|c|c|c|c|c|c|}
\hline & Right VCI $(n=25)$ & Left VCI $(n=46)$ & Bilateral VCI $(n=23)$ & p-value ${ }^{a, b)}$ & p-value ${ }^{c)}$ \\
\hline Age (yr) & $53.24 \pm 16.98$ & $56.26 \pm 17.93$ & $60.78 \pm 16.35$ & 0.321 & \\
\hline Sex, male & $14(56.0)$ & $22(47.8)$ & $13(56.5)$ & 0.715 & 0.511 \\
\hline \multicolumn{6}{|l|}{ Past history } \\
\hline Diabetes mellitus & $2(8.0)$ & $7(15.2)$ & $3(13.0)$ & 0.734 & 0.556 \\
\hline Hypertension & $6(24.0)$ & $13(28.3)$ & $4(17.4)$ & 0.546 & 0.931 \\
\hline Heart disease & $0(0.0)$ & $4(8.7)$ & $1(4.3)$ & 0.248 & 0.129 \\
\hline Stroke & $1(4.0)$ & $2(4.3)$ & $3(13.0)$ & 0.381 & 0.919 \\
\hline Cancer & $8(32.0)$ & $15(32.6)$ & $9(39.1)$ & 0.499 & 0.360 \\
\hline Thyroid disease & $7(28.0)$ & 7 (15.2) & $5(21.7)$ & 0.833 & 0.598 \\
\hline Thyroid operation & $5(20.0)$ & $2(4.3)$ & $2(8.7)$ & 0.251 & 0.191 \\
\hline Trauma & $6(24.0)$ & $5(10.9)$ & $0(0.0)$ & 0.051 & 0.262 \\
\hline Intubation & $10(40.0)$ & $16(34.8)$ & $14(60.9)$ & $0.044^{*}$ & 0.929 \\
\hline Infection & $5(20.0)$ & $12(26.1)$ & $5(21.7)$ & 0.801 & 0.884 \\
\hline \multicolumn{6}{|l|}{ Subjective symptoms } \\
\hline Voice change & $17(68.0)$ & $31(67.4)$ & $15(65.2)$ & 0.982 & 0.914 \\
\hline Hoarseness & $17(68.0)$ & $32(69.6)$ & $14(60.9)$ & 0.941 & 0.758 \\
\hline Aphonia & $0(0.0)$ & $0(0.0)$ & $3(13.0)$ & $0.017^{*}$ & 1.000 \\
\hline Impaired high pitch & $15(60.0)$ & $26(56.5)$ & $14(60.9)$ & 0.819 & 0.649 \\
\hline Breathing difficulty & $3(12.0)$ & $4(8.7)$ & $1(4.3)$ & 0.880 & 0.645 \\
\hline Sore throat & $3(12.0)$ & $2(4.3)$ & $0(0.0)$ & 0.130 & 0.162 \\
\hline Aspiration during meal & $11(44.0)$ & $24(52.2)$ & $11(47.8)$ & 0.771 & 0.516 \\
\hline \multicolumn{6}{|l|}{ Physical examination } \\
\hline Palpable neck mass & $0(0.0)$ & $3(6.5)$ & $1(4.3)$ & 0.250 & 0.192 \\
\hline Impaired laryngeal elevation & $5(20.0)$ & $13(28.3)$ & $5(21.7)$ & 0.246 & 0.358 \\
\hline Decreased gag reflex & $5(20.0)$ & $5(10.9)$ & $3(13.0)$ & 0.509 & 0.459 \\
\hline Abnormal findings in VFSS & $5(20.0)$ & $9(19.6)$ & $10(43.5)$ & 0.056 & 0.972 \\
\hline
\end{tabular}

Values are presented as mean \pm standard deviation or number (\%).

VCI, vocal cord immobility; VFSS, videofluoroscopic swallowing study.

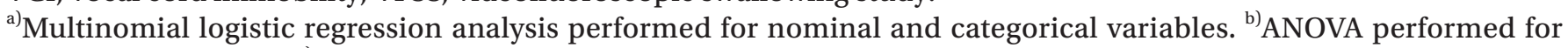
continuous variables. ${ }^{c)}$-value between right and left VCI groups by multinomial logistic regression analysis.

${ }^{*} \mathrm{p}<0.05$, significant difference.

All the other variables showed no significant correlation between three groups (Table 4).

\section{DISCUSSION}

In this study, the researchers analyzed clinical characteristics in patients with neurogenic and non-neurogenic causes of VCI. In the neurogenic group, impaired high pitched 'e' sound and aspiration symptoms were more common than the non-neurogenic group. Furthermore, hoarseness was more frequent in subjects who had recurrent laryngeal neuropathy.
Patients with VCI usually have one or more laryngeal nerve injuries and it can make inadequate closure or insufficiency of the glottis. These abnormalities are associated with breathing difficulty, dysphonia, and vocal fatigue. Also, neurogenic VCI can occur secondary to systemic disease, malignancy, and surgical interventions around the neck and thorax [2]. The surgery including thyroidectomy, esophagectomy, and lung resection can result in RLN injury due to anatomical course of RLN [2326]. In this study, cancer history was more common in the neurogenic VCI group than the non-neurogenic VCI group. 
The cricothyroid muscle is a key muscle in control of voice frequency, thus superior laryngeal neuropathy can cause poor vocal quality such as vocal cord asymmetry and acoustic aperiodicity [27]. On the other hand, SLN injury had no significant influence on glottal configuration and function in some previous studies [28]. Therefore, accurate diagnosis is important for a favorable treatment outcome of VCI $[17,29]$. In this study, the most common symptoms of both neurogenic and nonneurogenic VCI group were voice change and hoarseness. The $58.5 \%$ and $39.5 \%$ of neurogenic and nonneurogenic VCI groups had impaired high pitched 'e' sound, respectively. High pitched sound was known to be associated with the cricothyroid muscle innervated by SLN [20]. Among the 55 patients with impaired a highpitched sound in the neurogenic group, 25 patients had superior laryngeal neuropathy or both laryngeal nerve injuries (67.5\%). However, impaired high-pitched sound was also common in patients with recurrent laryngeal neuropathy (52.6\%). The recurrent laryngeal neuropathy is common in traumatic neurolaryngological lesion. Injury of RLN lead to flaccid ipsilateral vocal cord and it can lead to dysphonia or aphonia, hoarseness and aspiration into trachea [30]. Therefore, vocal cord paralysis can lead to impaired high-pitched sound due to a weak, breathy voice, inability to raise the volume of the voice, and the sensation of running out of air while speaking. In the subgroup analysis, hoarseness was significantly higher in patients with recurrent laryngeal neuropathy. Mild and persistent hoarseness can be detected as the only initial symptom of the patients with compression of RLN [31]. Therefore, recurrent laryngeal neuropathy should be suspected in patients who complain of sudden voice change and hoarseness.

Aspiration risk increased by $37 \%-50 \%$ in the patients with VCI [32] and dysphagia is common in VCI with SLN and/or RLN injuries [33]. Consistent with previous studies, $42.3 \%$ of the total VCI patients complained of aspiration during a meal, and the frequency was higher in the neurogenic VCI group than the non-neurogenic VCI group in this study. There was some controversy with the correlation of RLN and aspiration. Swallowing difficulty is not common in patients with only RLN injury [34], but, several reports argued that aspiration can happen in unilateral RLN paralysis [30,33].

In this study, abnormal VFSS findings, including pene- tration and aspiration, were reported in $21.1 \%$ of patients with only the recurrent laryngeal neuropathy group. Internal branch of the SLN have association with swallowing, laryngeal closure, and respiratory rhythm [35]. However, there were no patients with SLN injury that showed abnormal VFSS findings. In this study, the researchers enrolled 9 patients in only superior laryngeal neuropathy group, smaller than other groups. These patients were younger (mean age, 45.6 years) and showed lesser underlying diseases than RLN injury group. Also, no abnormal spontaneous activities with mild or chronic neuropathy patterns were detected in $66.7 \%$ of patients in SLN injury group. Because of these factors, the researchers could not conclude correlation of RLN, SLN with aspiration exactly in this study.

Many patients complained of pain and discomfort during LEMG. It is difficult to test because of problems in sampling small laryngeal muscles and interfering signals from neighboring muscles [22]. This test needs enough skillfulness to examine. Because of that, some clinicians omitted LEMG in VCI patients occasionally. Nevertheless, with neurologic, pathophysiologic results from LEMG, researchers can diagnose neurologic VCI, neuromuscular disease in larynx and determine the appropriate therapy method. Many authors consider LEMG to be an important tool and recommend its clinical use in patients with suspected VCI [36,37].

Limitations of our study were small sample size and retrospectively collected data. There were some findings not consistent with previous studies such as the relationship between dysphagia and SLN. The researchers also could not get the patients' whole information about prognosis because of loss of follow-up and missed medical records. A larger sample size with a prospective study will be needed for adequate statistical analysis and to investigate the clinical outcomes during the long-term follow up period in VCI patients.

In the patients with suspected vocal cord palsy, impaired high pitched 'e' sound and aspiration symptoms were more common in a group with neurogenic cause of VCI than a non-neurogenic group. Hoarseness was more frequent in subjects with recurrent laryngeal neuropathy than superior laryngeal neuropathy subjects. Thorough clinical evaluation and electrodiagnostic study of laryngeal muscle are important to differentiate the underlying cause of VCI. 


\section{CONFLICT OF INTEREST}

No potential conflict of interest relevant to this article was reported.

\section{ACKNOWLEDGMENTS}

This work was supported by the National Research Foundation of Korea (NRF) funded by the Korea government (No. 2016R1A2B4009206).

\section{REFERENCES}

1. Ahmad S, Muzamil A, Lateef M. A Study of incidence and etiopathology of vocal cord paralysis. Indian J Otolaryngol Head Neck Surg 2002;54:294-6.

2. Syamal MN, Benninger MS. Vocal fold paresis: a review of clinical presentation, differential diagnosis, and prognostic indicators. Curr Opin Otolaryngol Head Neck Surg 2016;24:197-202.

3. Xu W, Han D, Hou L, Zhang L, Zhao G. Value of laryngeal electromyography in diagnosis of vocal fold immobility. Ann Otol Rhinol Laryngol 2007;116:576-81.

4. Ingle JW, Young VN, Smith LJ, Munin MC, Rosen CA. Prospective evaluation of the clinical utility of laryngeal electromyography. Laryngoscope 2014;124:2745-9.

5. Weddell G, Feinstein B, Pattle E. The electrical activity of voluntary muscle in man under normal and pathological conditions. Brain 1944;67:178-257.

6. Faaborg-Andersen K, Buchthal F. Action potentials from internal laryngeal muscles during phonation. Nature 1956;177:340-1.

7. Faaborg-Andersen K, Edfeldt AW. Electromyography of intrinsic and extrinsic laryngeal muscles during silent speech: correlation with reading activity. Acta Otolaryngol 1958;49:478-82.

8. Buchthal F. Electromyography of intrinsic laryngeal muscles. Q J Exp Physiol Cogn Med Sci 1959;44:137-48.

9. Kotby MN. Percutaneous laryngeal electromyography. Standardization of the technique. Folia Phoniatr (Basel) 1975;27:116-27.

10. Guha K, Sabarigirish K, Singh SK, Yadav A. Role of laryngeal electromyography in predicting recovery after vocal fold paralysis. Indian J Otolaryngol Head Neck Surg 2014;66:394-7.

11. Smith LJ, Rosen CA, Munin MC. Vocal fold motion outcome based on excellent prognosis with laryngeal electromyography. Laryngoscope 2016;126:2310-4.

12. Pardo-Maza A, Garcia-Lopez I, Santiago-Perez S, Gavilan J. Laryngeal electromyography for prognosis of vocal fold paralysis. J Voice 2017;31:90-3.

13. Blitzer A. Spasmodic dysphonia and botulinum toxin: experience from the largest treatment series. Eur J Neurol 2010;17 Suppl 1:28-30.

14. Wang CC, Chang MH, Jiang RS, Lai HC, De Virgilio A, Wang CP, et al. Laryngeal electromyography-guided hyaluronic acid vocal fold injection for unilateral vocal fold paralysis: a prospective long-term follow-up outcome report. JAMA Otolaryngol Head Neck Surg 2015;141:264-71.

15. Bachor E, Bonkowsky V, Hacki T. Herpes simplex virus type I reactivation as a cause of a unilateral temporary paralysis of the vagus nerve. Eur Arch Otorhinolaryngol 1996;253:297-300.

16. Parano E, Pavone L, Musumeci S, Giambusso F, Trifiletti RR. Acute palsy of the recurrent laryngeal nerve complicating Epstein-Barr virus infection. Neuropediatrics 1996;27:164-6.

17. Parnes SM, Satya-Murti S. Predictive value of laryngeal electromyography in patients with vocal cord paralysis of neurogenic origin. Laryngoscope 1985;95:13236.

18. Rosenbek JC, Robbins JA, Roecker EB, Coyle JL, Wood JL. A penetration-aspiration scale. Dysphagia 1996; 11:93-8.

19. Perotto AO. Anatomical guide for the electromyographer: the limbs and trunk. 5th ed. Springfield: Charles C Thomas Publisher; 2011. p. 311-6.

20. Kimaid PA, Crespo AN, Moreira AL, Wolf AE, FrancaJr MC. Laryngeal electromyography techniques and clinical use. J Clin Neurophysiol 2015;32:274-83.

21. Garcia-Lopez I, Santiago-Perez S, Penarrocha-Teres J, del Palacio AJ, Gavilan J. Laryngeal electromyography in diagnosis and treatment of voice disorders. Acta Otorrinolaringol Esp 2012;63:458-64.

22. Sulica L, Blitzer A. Electromyography and the immobile vocal fold. Otolaryngol Clin North Am 2004;37:5974.

23. Booka E, Takeuchi H, Nishi T, Matsuda S, Kaburagi T, Fukuda K, et al. The impact of postoperative complications on survivals after esophagectomy for esophageal cancer. Medicine (Baltimore) 2015;94:e1369. 
24. Sato Y, Kosugi S, Aizawa N, Ishikawa T, Kano Y, Ichikawa $\mathrm{H}$, et al. Risk factors and clinical outcomes of recurrent laryngeal nerve paralysis after esophagectomy for thoracic esophageal carcinoma. World J Surg 2016;40:129-36.

25. Kurihara N, Imai K, Minamiya Y, Saito H, Takashima S, Kudo S, et al. Hoarseness caused by arytenoid dislocation after surgery for lung cancer. Gen Thorac Cardiovasc Surg 2014;62:730-3.

26. Calo PG, Medas F, Erdas E, Pittau MR, Demontis R, Pisano G, et al. Role of intraoperative neuromonitoring of recurrent laryngeal nerves in the outcomes of surgery for thyroid cancer. Int J Surg 2014;12 Suppl 1: S213-7.

27. Orestes MI, Chhetri DK. Superior laryngeal nerve injury: effects, clinical findings, prognosis, and management options. Curr Opin Otolaryngol Head Neck Surg 2014;22:439-43.

28. De Virgilio A, Chang MH, Jiang RS, Wang CP, Wu SH, Liu SA, et al. Influence of superior laryngeal nerve injury on glottal configuration/function of thyroidectomy-induced unilateral vocal fold paralysis. Otolaryngol Head Neck Surg 2014;151:996-1002.

29. Wang CC, Chang MH, De Virgilio A, Jiang RS, Lai HC, Wang CP, et al. Laryngeal electromyography and prognosis of unilateral vocal fold paralysis: a long-term prospective study. Laryngoscope 2015;125:898-903.

30. Crumley RL. Unilateral recurrent laryngeal nerve pa- ralysis. J Voice 1994;8:79-83.

31. Paquette CM, Manos DC, Psooy BJ. Unilateral vocal cord paralysis: a review of CT findings, mediastinal causes, and the course of the recurrent laryngeal nerves. Radiographics 2012;32:721-40.

32. Leder SB, Suiter DM, Duffey D, Judson BL. Vocal fold immobility and aspiration status: a direct replication study. Dysphagia 2012;27:265-70.

33. Bou-Malhab F, Hans S, Perie S, Laccourreye O, Brasnu D. Swallowing disorders in unilateral recurrent laryngeal nerve paralysis. Ann Otolaryngol Chir Cervicofac 2000;117:26-33.

34. Taniyama Y, Miyata G, Kamei T, Nakano T, Abe S, Katsura K, et al. Complications following recurrent laryngeal nerve lymph node dissection in oesophageal cancer surgery. Interact Cardiovasc Thorac Surg 2015; 20:41-6.

35. Jafari S, Prince RA, Kim DY, Paydarfar D. Sensory regulation of swallowing and airway protection: a role for the internal superior laryngeal nerve in humans. J Physiol 2003;550(Pt 1):287-304.

36. Kimaid PA, Crespo AN, Quagliato EM, Wolf A, Viana MA, Resende LA. Laryngeal electromyography: contribution to vocal fold immobility diagnosis. Electromyogr Clin Neurophysiol 2004;44:371-4.

37. Rickert SM, Childs LF, Carey BT, Murry T, Sulica L. Laryngeal electromyography for prognosis of vocal fold palsy: a meta-analysis. Laryngoscope 2012;122:158-61. 